\title{
Global governance of antimicrobial resistance
}

Ensuring future generations have access to antimicrobials is high on the agenda for many heads of state, and almost all Ministers of Health. Following the UN General Assembly's 2016 highlevel meeting on antimicrobial resistance (AMR), an ad hoc Interagency Coordination Group (IACG), co-chaired by the UN Deputy Secretary-General and the Director-General of WHO, was tasked with providing guidance to political leaders on approaches needed to promote sustainable action on AMR. ${ }^{1}$

Failure to tackle AMR threatens the attainment of various Sustainable Development Goals (SDGs)-including those on poverty reduction, reduced inequalities, clean water, and sanitation-and progress already made will be lost. ${ }^{2,3}$ With just over 12 months remaining until the IACG is due to report back to the UN Secretary-General, its recommendations must seek to improve the global governance of AMR for the long term while supporting the development of a "21st century UN". 4

The rising threat of AMR in humans is neither new nor rare; drug-resistant infections are already estimated to cause 700000 annual deaths globally. ${ }^{5} \mathrm{~A}$ leading concern is multidrugresistant tuberculosis that resulted in 240000 deaths worldwide in $2016 .{ }^{6}$ The emergence of resistance is a natural phenomenon but is accelerated by a complex combination of human activity in health care, agriculture (including animal husbandry, aquaculture, and crops), and environmental contamination..$^{7,8}$

The costs of not addressing the rising rates of AMR could lead to an annual reduction in global gross domestic product of $3 \cdot 8 \%$ by $2050 .^{3}$ Low-income and middle-income countries (LMICS) 
are set to be hit the hardest, and will almost certainly experience increased poverty and inequality as a result of $\mathrm{AMR} .^{3}$ Further, the appropriate and inappropriate use of antimicrobials, particularly antibiotics, leads to resistance that takes human lives. However, in many countries lack of access to safe and affordable antimicrobials results in an increased mortality burden; an estimated $5 \cdot 7$ million deaths annually are the result of a lack of access to antibiotics. ${ }^{9}$

There is an emerging consensus that efforts to contain the threat of AMR should focus on four key objectives. First, ensure appropriate use of antibiotics in both human and animal health, over time eliminating the unnecessary use of antibiotics for growth promotion in agriculture. Second, eradicate untreated effluent in both animal and human health. Third, improve prevention of AMR with infection prevention and control (ICP) and water, sanitation, and hygiene (WASH) programmes in all sectors. Finally, ensure that all who need them have appropriate access to a regulated supply of quality-assured, affordable antimicrobials. ${ }^{10}$ These global objectives should be supported by the appropriate development and stewardship of new diagnostics and vaccines, as well as new antibiotics and alternatives.

The Tripartite Collaboration on AMR is the current UN-focused governance arrangement, comprising WHO, the Food and Agriculture Organization of the United Nations (FAO), and the World Organisation for Animal Health (OIE). However, there are limitations with this governance arrangement. Global public goods such as antimicrobials can only be preserved if all countries cooperate. A multistakeholder, multisectoral, and truly global response to AMR is required. This response needs to be reinforced by stronger global governance that has a mandate across health, agriculture, and the environment and is supported by a well resourced secretariat. ${ }^{11}$ This approach would include four elements. First, an effective mandate to 
encourage countries to make binding national commitments with support provided to strengthen capacity, capability, and funding for alternatives to antimicrobials and innovations in LMICs. Second, a process for reporting on these commitments. Third, the capacity, ability, and authority to advocate for AMR. Fourth, the ability to mobilise all stakeholders, including the private sector, civil society, and philanthropic actors.

To inform the recommendations of the IACG to the UN Secretary-General, a small initial meeting of stakeholders was convened at Leeds Castle in the UK under the leadership of Dame Sally Davies, Chief Medical Officer (CMO) for England, member of the IACG, and Chair of the subgroup on SDG alignment, global governance post 2019, and UN role and responsibilities. Representatives included the Tripartite authorities, the private sector, and academic and multilateral experts.

The meeting concluded that a future international legal agreement is urgently needed to lock in long-term international standards and norms across the private and public sectors and ensure that antibiotics are available for future generations. ${ }^{12}$ Reaching such an ambitious legal agreement will take leadership, skill, and perseverance from a wide range of actors. The group recommended that this might best be supported by the development of a multisector, multistakeholder Global Steering Board (figure) to be hosted in an existing organisation led by a time-limited High-Level AMR Commission. Under this model, the international legal agreement would be designed through collaboration of the Commission and members states, and then enforced by the Global Steering Board and the Tripartite Collaboration on AMR. 
The High-Level AMR Commission (see figure 1) would be led by political, industry, and civil society leaders, and would be supported by the efforts of the Global Steering Board. The Board will undertake the following functions: deliver programmes of work aligned to key priorities; monitor and report progress, course correct, and challenge overall progress; connect stakeholders and professional groups across the private, public, and civil society sectors; and strengthen existing efforts of the Tripartite-in addition to the UN Environment Programme (UNEP) that will continue to provide normative guidance, drive standards, and monitor countryby-country data. The work of the Board would be supported by an expert advisory panel, similar to the Intergovernmental Panel on Climate Change, to provide independent advice on multisector scientific and policy questions to inform the setting of an appropriate suite of global goals to contain the threat of AMR, analogous to the climate change target of limiting global temperature rise to $2^{\circ} \mathrm{C}$ above pre-industrial levels.

The danger of AMR moving across borders demands the strengthening of global governance arrangements; no country can avoid the consequences if antimicrobials become ineffective. Effective action is only possible if all countries, agencies, and other actors organise ourselves across national boundaries. The focused set of priorities for AMR governance, the international legal process needed to deliver on these, and the supporting High-Level AMR Commission and Global Steering Board that we propose are only part of the solution. A truly global response to reduce the threat of AMR requires everyone to play their part. We welcome discussion on what the functions of the Global Steering Board could be. 
Global Governance for Antimicrobial Resistance

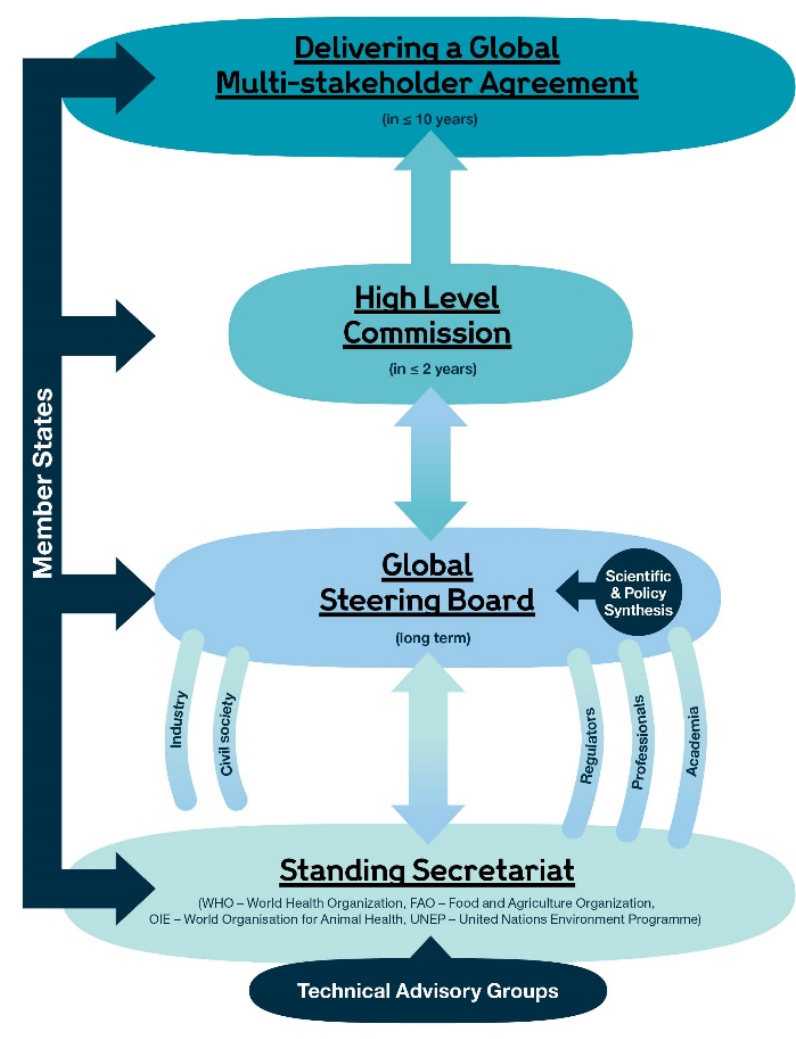

Figure 1: Global governance for antimicrobial resistance proposal FAO = Food and Agriculture Organization of the United Nations; OIE = World Organisation for Animal Health; UNEP = UN Environment Programme 
Connor Rochford, Devi Sridhar, Ngaire Woods, Zia Saleh, Lars Hartenstein, Hemant Ahlawat, Ed Whiting, Mark Dybul, Otto Cars, Eric Goosby, Andrew Cassels, German Velasquez, Steven Hoffman, Enis Baris, Jonathan Wadsworth, *Sally Davies

Blavatnik School of Government, University of Oxford, Oxford, UK (CR, NW, ZS); Global Health Governance Programme, The University of Edinburgh, Edinburgh, UK (DS); Wellcome Trust, London, UK (EW); McKinsey and Company, Social Sector Hub, Geneva, Switzerland (LH, HA); Center for Global Health and Quality, Georgetown University, Washington, DC, USA (MD); Department of Medical Sciences, Uppsala University, Uppsala, Sweden (OC); Institute for Global Health Sciences, University of California, San Francisco, San Francisco, CA, USA (EG); Special Adviser for Health and Development, South Centre, Geneva, Switzerland (GV); Global Health Centre, The Graduate Institute, Geneva, Switzerland (AC); Global Strategy Lab, York University, York, UK (SH); World Bank Group, Washington, DC, USA (EB, JW); and Department of Health, London SE1 6LH, UK (SD) sally.davies@dh.gsi.gov.uk CR, DS, NW, and ZS have received personal fees (consulting fees) from Wellcome Trust. LH, $\mathrm{HA}, \mathrm{EW}, \mathrm{MD}, \mathrm{OC}, \mathrm{EG}, \mathrm{AC}, \mathrm{GV}, \mathrm{SH}, \mathrm{EB}, \mathrm{JW}$ and SD declare no competing interests. The findings, interpretations, and conclusions expressed in this Comment are entirely those of the authors. They do not necessarily represent the views of the International Bank for Reconstruction and Development/World Bank and its affiliated organisations, or those of the Executive Directors of the World Bank or the governments they represent. The Leeds Castle meeting and supporting studies was made available thanks to funding from the Wellcome Trust. Participants at the Leeds Castle meeting included Nana Kuo, Simon Bland, Richard 
Sibbel, Elizabeth Cousens, Silvia Gold, Arianna Giuliodori, Thomas Cueni, Muzammil Mansuri, Lucy Chen, and John Reed.

1 Interagency Coordination Group (IACG) on Antimicrobial Resistance. Work plan of the Adhoc Interagency Coordination Group on Antimicrobial Resistance May 2017-September 2019.IACG, 2017 http://www.who.int/antimicrobial-resistance/interagency-coordinationgroup/FINAL_IACG_DRAFT_WORKPLAN.pdf (accessed May 1, 2018).

2 Interagency Coordination Group (IACG) on Antimicrobial Resistance. AMR Framework for Action supported by the IACG Working Document. IACG, 2017 http://www.who.int/antimicrobial-resistance/interagency-coordinationgroup/20170818_AMR_FfA_v01.pdf_(accessed May 1, 2018).

3 World Bank. Drug-resistant infections: a threat to our economic future (discussion draft). World Bank, 2016. http://pubdocs.worldbank.org/en/527731474225046104/AMRDiscussion-Draft-Sept18updated.pdf (accessed May 1, 2018).

4 United Nations Secretary-General. Secretary-General's remarks to Economic and Social Council on Repositioning the UN Development System to Deliver on the 2030 Agenda United Nations, 2017. https://www.un.org/sg/en/content/sg/statement/2017-0705/secretary-generals-remarks-economic-and-social-council-repositioning_(accessed May 1, 2018).

5 O'Neill J. Tackling drug-resistant infections globally: final report and recommendationsthe review on antimicrobial resistance. 2016. https://amrreview.org/sites/default/files/160525_Final\%20paper_with\%20cover.pdf (accessed May 11, 2018). 
6 WHO. Multidrug-resistant tuberculosis (MDR-TB) 2017 update. 2017.

http://www.who.int/tb/challenges/mdr/MDR-RR_TB_factsheet_2017.pdf?ua=1 (accessed May 1, 2018).

7 Holmes AH, Moore LS, Sundsfjord A, et al. Understanding the mechanisms and drivers of antimicrobial resistance. Lancet 2016; 387: 176-87.

8 WHO. Antimicrobial resistance. 2018. www.who.int/mediacentre/factsheets/fs194/en/ (accessed May 1, 2018).

9 Daulaire N, Bang A, Tomson G, Kalyango JN, Cars O. Universal access to effective antibiotics is essential for tackling antibiotic resistance. J Law Med Ethics 2015; 43: 17-21.

10 Wernli D ,Jørgensen PS, Morel CM, et al. Mapping global policy discourse on antimicrobial resistance. BMJ Global Health 2017; 2: e000378.

11 Barret S. Why cooperate?: the incentive to supply global public goods. Oxford: Oxford University Press, 2007.

12 Padiyara P, Inoue H, Sprenger M. Global governance mechanisms to address antimicrobial resistance. Infect Dis (Auckl) 2018; 11: 1178633718767887. 